\title{
FormaÇão, PROFISSIONALIZAÇão E VALORIZAÇÃO dO PROFESSOR SURDO: REFLEXõES A PARTIR DO DECRETO 5.626/2005
}

\author{
FORMATION, PROFESSIONALIZATION AN D VALUEIN G OF DEAF TEACHERS: REFLECTIONS AFTER \\ THE DeCREe 5.626/2005
}

\author{
Juliana Guimarães FA RIA ${ }^{1}$
}

\begin{abstract}
RESU M 0: o texto apresenta como tema reflexões sobre o Instrutor de Libras e o Professor de Libras dentro da escola de Educação Básica. Tem como objetivo refletir sobre o significado da denominação de Instrutor dada ao profissional surdo e compreender de que maneira essa denominação está expressa no Decreto 5.626/ 2005. A partir dessa reflexão, verifica-se que o Instrutor de Libras caracterizado no Decreto é de um profissional que não possui formação pedagógica, porém é citado de forma alternativa ao papel desempenhado pelo Professor deLibras dentro da escola de Educação Básica. Verifica-se, ainda, queInstrutor de Libras tem sido a denominação dada ao profissional surdo, mesmo quando ele exerce atividade peculiar à docência e possui formação pedagógica. Assim, evoca-se que a busca por uma educação que considere a cultura, identidade e processo de aprendizagem do surdo será al cançada mediantea primazia de profissional ização, reconhecimento eval orização dos próprios profissionais surdos dentro das escolas de Educação Básica. Essa valorização passa pelo reconhecimento do profissional surdo que ensina Libras como um Professor de Libras, sendo um profissional que participa dos debates e tomadas de decisão, e se envolve no processo educativo de seus pares.
\end{abstract}

PALAVRAS-CHAVE: Educação Especial. Formação. Profissionalização. Professor Surdo.

A BSTRACT: The paper presents reflections on the theme Sign Language - Libras Instructor and Teacher of Libras within basic education schools (elementary, middle and high school education). The study aims to reflect on the meaning of the name instructor attributed to the deaf professional in order to understand how that term is reflected in the 5626/ 2005 Decree. Studying this designation, it appears that the instructor is characterized by the Decree as a professional who does not have pedagogical training, though he or she is expected to play an alternate role to the Libras teacher within basic education schools. Also, the term Libras Instructor has been used to designate deaf professional, even when they exercise activities related to teaching and havecompleted pedagogical training. Thus, the undertoneis that the search for an education that considers culture, identity and learning processes of the deaf will be achieved by the primacy of professionalization, recognition and appreciation of deaf professionals themsel ves within basic education schools. This appreciation includes the recognition of deaf professionals that teach Libras as a Libras Teacher that should participate in debates and decision making, and should be involved in the educational process of their peers.

KEYWO RD S: Special Education. Brazilian Sign Language. Interpreter for Deaf Students.

\footnotetext{
${ }^{1}$ Doutorado em Educação na FE/ UFG e professora efetiva da Faculdade de Letras/ UFG, no Departamento de Estudos Linguísticos e Literários, no curso de Letras: Libras. julianagf@yahoo.com.br
} 


\title{
1 INTRODUÇÃo
}

A política de formação de professores é uma discussão que se intensificou nas últimas décadas durante o debate eposterior aprovação da Lei de Diretrizes e Bases da Educação Nacional - LDB 9.694/96. A referida legislação elevou a formação de professores para o nível superior, estabel eceu quetal formação aconteça em Universidades ou Institutos Superiores de Educação. Trouxe consigo a busca pela valorização e profissional ização do profissional da educação.

Tanuri (2000) considera que a aprovação da LDB vem para superar, de certa forma, a polêmica rel ativa à formação de professores entre o nível superior e o nível médio, numa luta dos educadores brasileiros no processo de melhoria da qualidade da educação e valorização do profissional da educação. Os cursos Normais de nível médio, os chamados Magistério, foram aceitos como formação mínima apenas em período transitório, conforme o artigo 87, parágrafo 4 ㅇ.

\section{O artigo $62^{2}$ da LDB 9.694/ 96 diz que:}

A rt. 62. A formação de docentes para atuar na educação básica far-se-á em nível superior, em curso de licenciatura, de graduação plena, em universidades e institutos superiores de educação, admitida, como formação mínima para o exercício do magistério na educação infantil enas quatro primeiras séries do ensino fundamental, a oferecida em nível médio, na modalidade Normal.

Conforme mencionado, o parágrafo $4^{0}$ do artigo 87 das Disposições Transitórias da LDB, acrescenta que:

\begin{abstract}
Art. 87. É instituída a Década da Educação, a iniciar-se um ano a partir da publicação desta Lei.

§ 4 o A té o fim da Década da Educação somente serão admitidos professores habilitados em nível superior ou formados por treinamento em serviço.
\end{abstract}

A partir desse dispositivo legal, acirraram-se ainda mais os debates sobre a política de formação dos profissionais da educação no Brasil. O debate traçado gira em torno de al gumas temáticas, versam sobre o modelo de formação de professores, as questões de aligeiramento da formação, o curso de Pedagogia em relação ao curso Normal Superior, as mudanças na Educação Básica trazida pela LDB e a formação de professores para essa real idade, dentre outros. Porém, durantetodos esses anos de debate, éconsenso entre os educadores quea formação

\footnotetext{
${ }^{2}$ Durante a elaboração desse texto, encontrava-se aprovado na Comissão de Educação, Cultura e Esporte do Senado Federal na data de 06/ 07/ 2010 uma alteração na LDB 9694/ 96 (emenda substitutiva № 01 - CE) dos artigos 62 e87, no qual será permitido ingresso na carreira do magistério no setor público com apenas o ensino médio, na modalidade normal, porém, se dentro de 06 anos o professor não concluir a formação superior, será considerado inabilitado para o exercício da profissão.
} 
dos profissionais da educação em nível superior em cursos de licenciatura é essencial tanto para a qualidade da educação, quanto para a profissionalização docente.

Dentro de uma política de ações afirmativas, em 2005, é aprovado o Decreto Presidencial 5.626 que, ao tratar da Regulamentação da Lei da Libras 10.436/ 2002, regula, al ém de outras ações, a questão da formação do Professor de Libras. A o examinar o Capítulo III do referido Decreto, é possível se deparar com dois personagens: o Professor de Libras e o Instrutor de Libras.

À primeira vista, as questões levantadas são: qual a diferença entre esses dois personagens? Qual o papel de cada um no campo da docência no ensi no de Libras? De que forma cada um interfere, ou não, na atuação do outro? Em essência: o que difere o Professor do Instrutor?

Essas são as problematizações que motivam as reflexões expressas nas próximas linhas. Não éintuito esgotar a temática eresponder a todas essas questões. Ademais, não será possível tratar nesse escrito sobre os processos e práticas pedagógicas, os saberes escolares no ensino da Libras, as representações dos atores envolvidos eas questões de produção epublicações da imprensa acadêmi ca, sendo estes, seguramente, objetos de potenciais sínteses futuras. Procura-se nesseartigo, tão somente, fazer uma reflexão sobre o texto legal expresso no Decreto 5.626/ 2005, e demais legislações, em relação ao Instrutor e ao Professor de Libras. A pós isso, refl etir sobrea profissional ização, formação eval orização do profissional com surdez atuante nas escolas no ensino de Libras.

\section{Q uestões sobre o Professor e Instrutor de Libras na Educação Básica: reflexões A PARTIR do DeCRETo 5.626/2005}

É inegável o avanço obtido em relação ao sujeito surdo, à Libras e às políticas linguísticas no Brasil após a aprovação do Decreto 5.626/ 2005 (QUADROS; PATERNO, 2006; FELIPE, 2006). Considera-se que o avanço trazido pelo Decreto é muito maissignificativo do queas normativas implementadas anteriormente, como: a Lei 10.098 de 2000, no seu artigo $18^{3}$, que anunciou a responsabilidade do Poder Público para implementar a formação de profissionais intérpretes de Libras; ea Lei 10.436/ 2002 que instituiu oficialmente a Libras como meio de comunicação e expressão edeterminou a obrigatoriedade do ensino da Libras em cursos deformação de professores e de fonoaudiólogos ${ }^{4}$. Tal significância do Decreto se justifica por

\footnotetext{
${ }^{3}$ Art. 18. O Poder Público implementará a formação de profissionais intérpretes de escrita em braile, linguagem de sinais e de guias-intérpretes, para facilitar qualquer tipo de comunicação direta à pessoa portadora de deficiência sensorial e com dificuldade de comunicação.

${ }^{4} \mathrm{Art} .4^{\circ} \mathrm{O}$ sistema educacional federal e os sistemas educacionais estaduais, municipais e do Distrito Federal devem garantir a inclusão nos cursos de formação de Educação Especial, de Fonoaudiologia e de Magistério, em seus níveis médio e superior, do ensino da Língua Brasileira de Sinais - Libras, como parte integrante dos Parâmetros Curriculares Nacionais - PCNs, conforme legislação vigente.
} 
explicitar mecanismos imperativos eações públicas para a formação de profissionais para o ensino, interpretação e tradução da Libras, ações afirmativas para usuários da Librasea sua expansão. Essa conquista éoriunda deum contexto histórico-político e social de movimento pelos direitos humanos e direitos linguísticos, com debates, ações e muitas lutas da comunidade surda em âmbito nacional einternacional, que foram bem explorados em diversas publicações, como as de Mazzotta (2005), Soares (2005), Felipe (2006), Quadros (2006) e Quadros et al. (2009).

Quadros et al. (2009) lembram que a atuação do professor de Libras está associada a diferentes contextos, alternando entre ensino de primeira língua e ensino de Libras como segunda língua, podendo ser: ensino de Libras para pessoas diversas ligadas ao surdo, como familiares eamigos; ensino de Libras na Educação Superior nos cursos de Fonoaudiologia e de Formação de Professores; ensino de Libras nas escolas de Educação Básica que possuam alunos surdos matriculados (nessa dimensão, poderá acontecer tanto como primeira língua para os surdos, como segunda língua para os alunos ouvintes que convivem com os surdos). Os autores ressal tam, ainda, a importância do ensino de Libras, como primeira língua, ser uma função a ser exercida por profissionais também surdos. Nessa mesma linha, Lunardi (1998, p.85) argumenta:

A presença do professor surdo na escola representa muito mais que modelo de linguagem e identidade: ele é um articulador do senso de cidadania que se estabelecenum processo derelação social. Essa relação aconteceentre professores surdos e alunos surdos, porque essa troca social de conhecimentos se reproduz através da língua de sinais.

O Decreto 5.626/ 2005 é um instrumento legal que traz esse apontamento, ou seja, a formação do professor de Libras deve ser oferecida, preferencialmente, ao profissional surdo (Art. 40, Art. 50eArt. 6\%). Sobrea Formação do Professor de Libras e do Instrutor de Libras, no Capítulo III do Decreto 5.626/ 2005 é explicitado:

Art. 40 A formação de docentes para o ensino de Libras nas séries finais do ensino fundamental, no ensino médio ena educação superior deve ser real izada em nível superior, em curso de graduação de licenciatura plena em Letras: Libras ou em Letras: Libras/ Língua Portuguesa como segunda língua.

Parágrafo único. As pessoas surdas terão prioridade nos cursos de formação previstos no caput.

Art. 5o A formação de docentes para o ensino de Libras na educação infantil e nos anos iniciais do ensino fundamental deve ser realizada em curso de Pedagogia ou curso normal superior, em que Libras eLíngua Portuguesa escrita tenham constituído línguas de instrução, viabilizando a formação bilíngue.

$\S 1$ o Admite-secomo formação mínima de docentes para o ensino de Libras na educação infantil enos anos iniciais do ensino fundamental, a formação ofertada em nível médio na modalidade normal, que viabilizar a formação bilíngue, referida no caput.

$\S$ 2 A s pessoas surdas terão prioridade nos cursos de formação previstos no caput. Art. 6o A formação de instrutor de Libras, em nível médio, deve ser realizada por meio de: 
I - cursos de educação profissional:

II - cursos de formação continuada promovidos por instituições de ensino superior; e III - cursos deformação continuada promovidos por instituições credenciadas por secretarias de educação.

§ 1o A formação do instrutor de Libras pode ser realizada também por organizações da sociedade civil representativa da comunidade surda, desde que o certificado seja convalidado por pelo menos uma das instituições referidas nos incisos II elll.

$\S$ 2ㅇ As pessoas surdas terão prioridadenos cursos deformação previstos no caput (grifo nosso).

Percebe-se que o artigo 6 permite que se faça a diferenciação entre o Professor e o Instrutor de Libras. Ao Instrutor não está explícito a necessidade de formação pedagógica, sendo uma denominação de pessoas formadas em cursos de formação profissional em nível médio. Já o Professor de Libras é todo aquele com formação pedagógica: tanto em nível médio, como em curso na modalidade Normal, quanto em nível superior, formado em Pedagogia, desde que tenha sido viabilizada a formação bilíngue; e no curso de Letras: Libras ou Letras: Libras/ Língua Portuguesa. Considerando que o Decreto foi publicado em 2005, situado, ainda, dentro da chamada Década da Educação, como explicitado no Art. 87 da LDB 9.694/ 96, a formação do professor em nível médio era admitida somente até ano de 2007, por conta do que expressa o parágrafo 40 do referido artigo, já citado anteriormente.

Assim, o Decreto 5.626/ 2005 vêm apresentar a área do conhecimento da Libras como disciplina curricular e conteúdo a ser ensi nado em diversos níveis emodalidades da educação. Para tal atividade profissional, apresenta quea função docente poderá ser exercida pelo Instrutor de Libras, da mesma forma que o Professor de Libras (art. 8o, § 2으) após um exame de proficiência:

Art. 8 O exame deproficiência em Libras, referido no art. 7ํ, deveavaliar a fluência no uso, o conhecimento e a competência para o ensino dessa língua.

§ 2o A certificação de proficiência em Libras habilitará o instrutor ou o professor para a função docente (grifo nosso).

Assim, ficam algumas questões: qual o papel do denominado "Instrutor de Libras" dentro da escola de Educação Básica, já que essa denominação não identifica, de acordo com o Decreto 5.626/ 2005, um profissional com formação pedagógica? Para o profissional surdo licenciado, porque não usar somente a nomenclatura de "Professor deLibras"? Um Decreto Presidencial tem força jurídica suficiente para certificar para a função docente no Brasil sem que a formação pedagógica esteja explicitamente garantida, quebrando uma conjuntura legal impressa na LDB 9694/ 1996, como aponta o parágrafo 2o do artigo 8o, em que habilita, por meio de exame de proficiência e certificação, o chamado ProLibras, o Instrutor para a função docente? 
Além do que, de acordo com o Decreto, o Instrutor só é citado para atuar na educação formal ${ }^{5}$ no Brasil, nos cursos de graduação e pós-graduação, até o fim da década do Decreto, desde que tenha a Certificação do ProLibras, como pode ser observado no que está explicitado no art. 70:

\begin{abstract}
Art. 7o Nos próximos dez anos, a partir da publicação deste Decreto, caso não haja docente com título de pós-graduação ou de graduação em Libras para o ensino dessa disciplina em cursos de edu cação superior, el a poderá ser ministrada por profissionais que apresentem pelo menos um dos seguintes perfis:

I - professor de Libras, usuário dessa língua com curso de pós-graduação ou com formação superior e certificado de proficiência em Libras, obtido por meio de exame promovido pelo Ministério da Educação;

II - instrutor de Libras, usuário dessa língua com formação de nível médio e com certificado obtido por meio de exame de proficiência em Libras, promovido pelo Ministério da Educação (grifo nosso).
\end{abstract}

Isso indica que o profissional que se caracteriza como "Instrutor de Libras" não está legalmente apto para atuar na docência em escola de Educação Básica no Brasil. Caso tenha formação pedagógica, em cursos de licenciatura, já não é Instrutor, mas sim Professor.

Sobre os profissionais para atuar na Educação Básica, estes estão categorizados em três grupos: professores habilitados, profissionais pedagogos e trabal hadores em educação, conforme descrito na Lei 12.014/ 2009 que altera o art. 61 da LDB:

Art. 1o O art. 61 da Lei no 9.394, de 20 de dezembro de 1996, passa a vigorar com a seguinte redação:

Art. 61. Consideram-se profissionais da educação escolar básica os que, nela estando em efetivo exercício e tendo sido formados em cursos reconhecidos, são: I - professores habilitados em nível médio ou superior para a docência na educação infantil e nos ensinos fundamental e médio;

II - trabalhadores em educação portadores de diploma de pedagogia, com habilitação em administração, planejamento, supervisão, inspeção e orientação educacional, bem como com títulos de mestrado ou doutorado nas mesmas áreas; III - trabalhadores em educação, portadores de diploma de curso técnico ou superior em área pedagógica ou afim.

N essas condições, o Instrutor de Libras, conforme descrito no Decreto 5.626/ 2005, é considerado como um trabalhador da educação, porém sem habilitação para a docência aos alunos de educação básica. Mesmo que o art. 80 do Decreto 5.626/ 2005 confira habilitação para a função docente, tem-sequeconsiderar quea análise de um instrumento jurídico não pode ser feita baseada apenas de um único parágrafo ou artigo isoladamente. É preciso visualizar a conjuntura no qual está inserido. Assim, o artigo 8ㅇ, citado anteriormente, se refere ao artigo 70, que

\footnotetext{
5 Por educação Formal entendem-se aquelas autorizadas, regulamentadas e avaliadas pelo poder público, como escolas de educação básica e superior. As escolas de cursos livres são consideradas como não-formais.
} 
trata apenas do exercício do Instrutor de Libras no ensino superior: graduação e pós-graduação. Consequentemente, a função docente a que se refere o artigo 80 é para esse nível de ensino.

Nesse contexto, de acordo com os dispositivos legais citados, tem-se o Professor de Libras licenciado como referência, na educação básica, sendo o profissional habilitado para o ensino dessa língua aos educandos, conformegarante direito do aluno surdo prescrito no Decreto 5.626/ 2005, artigo 15.

Porém, o mesmo instrumento legal cita a presença do Instrutor deLibras na escola, quando em seu artigo 14 estabelece que as instituições federais devem prover as escolas com profissionais que atuem como tradutores, professores e instrutores:

Art. 14. As instituições federais de ensino devem garantir, obrigatoriamente, às pessoas surdas acesso à comunicação, à informaçãao e à educação nos processos seletivos, nas atividades enos conteúdos curriculares desenvolvidos em todos os níveis, etapas e modalidades de educação, desde a educação infantil atéà superior.

$\S$ 1o Para garantir o atendimento educacional especializado eo acesso previsto no caput, as instituições federais de ensino devem:

III - prover as escolas com:

a) professor de Libras ou instrutor de Libras;

b) tradutor eintérprete de Libras - Língua Portuguesa;

c) professor para o ensino de Língua Portuguesa como segunda língua para pessoas surdas; e

d) professor regente de classe com conhecimento acerca da singularidade linguística manifestada pelos alunos surdos (grifo nosso)

Percebe-sequea presença do Instrutor de Libras na escola deEducação Básica é citada no artigo 14 de forma indiscriminatória ao Professor de Libras, usando a conjunção disjuntiva 'ou' para el encar esses dois profissionais dentro de uma mesma função profissional. Significa que o Decreto indica que o Professor de Libras pode exercer a função de Instrutor, porém, o Instrutor não está apto a atuar em espaços profissionais que exigem formação pedagógica. Ou seja, a interpretação quesefaz équeo Instrutor de Libras pode apoiar a escola, mas não éum professor. Ora, essa perspectiva diferencial de nomenclatura não faz sentido se o lócus de atuação éa escola de Educação Básica e sea atividade exercida tem como essência o processo ensino-aprendizagem da Libras para os educandos surdos. É tratar o Instrutor com certo desprestígio, mesmo se a função desempenhada possui relevância, por se tratar de uma prática docente. O quetem acontecido comumente équetanto os profissi onais surdos com licenciatura, quanto os profissionais surdos sem habilitação para o magistério, estão sendo alocados nas redes de ensino como Instrutores de Libras. As Diretrizes Operacionais ${ }^{6}$ das redes públicas de ensino

\footnotetext{
${ }^{6}$ No Estado de Santa Catarina, por exemplo, a "Instrução N ormativa/ SED N ${ }^{\circ} 04 / 2010$ " trata o instrutor de Libras dentre das responsabilidades de um professor: " 9.230 s professores autorizados para atuarem em Serviços de Atendimento Educacional Especializado - SAEDES e Atendimentos em Classe ( 2 o professor de turma,
} 
muitas vezes tratam indiscriminadamente esses dois personagens, deixando somente a surdez ou não surdez determinar se será denominado de Instrutor ou Professor. Seésurdo, então élnstrutor de Libras, independenteseo profissional já possui habilitação para o magistério ou está em processo de formação em serviço para licenciar-se.

Nessa linha, Silveira e Rezende (2008), ao analisarem reportagens publicadas na Revista N ova Escola sobre a educação de surdos, trazem algumas reflexões:

Quão inferior o surdo se apresenta no contexto profissional, já que no ambiente educacional foram observadas várias distorções, na nossa avaliação. Historicamente, fomos chamados para sermos o "dicionário ambulante" (de Libras) de muitos professores na escola e, na maior parte, os ditos "professores especialistas", como éo caso dos personagens consultados na reportagem, apenas orientavam os alunos a trabal harem com o sinal dado pelos surdos. Por que o surdo não pode desempenhar este importante papel de professor e não de mero instrutor - palavra com menor status profissional? Por que el e não pode explicar os conteúd os curriculares, como já acontece em várias escolas? N esseúltimo caso, os surdos já trabal haram com informações importantes apresentadas pela disciplina e mesmo assi m não foram considerados, agraciados com o título de "professores" pel os docentes. Sempre os surdos foram considerados tecnicamente como instrutores, mas na verdade, atuavam como professores, apesar de poucos possuírem licenciatura (SILVEIRA; REZEN DE, 2008, p.66-67).

O embatetraçado éjustamente o reconhecimento, a profissionalização e a valorização do profissional surdo dentro da escola de educação básica. Para além de um 'dicionário ambulante de Libras' o profissional surdo, muitas vezes identificado como Instrutor, mesmo tendo formação pedagógica ecom licenciatura, está na escola para contribuir com o processo educativo de seus pares, na perspectiva da docência.

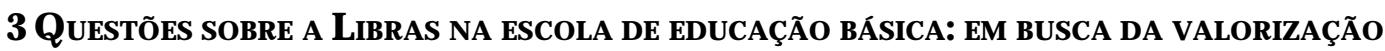 e profissionalização do Professor Surdo}

A menção do profissional denominado de Instrutor de Libras foi feita no Documento ‘A educação quenós surdos queremos', elaborado pela comunidade surda a partir do pré-congresso ao $\mathrm{V}$ Congresso Latino Americano de Educação Bilíngue para Surdos, realizado em Porto Alegre/ RS, no ano de 1999. Nesse documento, o Instrutor é descrito no campo quetrata da Formação do Profissional

professor bilíngue, professor intérprete de LIBRAS, instrutor de LIBRAS) não poderão, sob hipótese alguma, ser designados para atuarem em outra função naquel e contrato". Da mesma forma, o Estado de Goiás, nas suas Diretrizes Operacionais, o Instrutor de Libras deve ser surdo e pertence ao quadro de multiprofissionais junto à fonoaudiólogos, psicól ogos eintérpretes. A lém do que, em 2010, o Estado de Goiás fez concurso público para Instrutor de Libras e exigiu para a investidura no cargo a conclusão em qual quer curso de Licenciatura, porém com a certificação ProLibras. 
Surdo, em que o Instrutor assume o papel de ensinar a Libras em empresas e nas escolas, no ensino das famílias, caso não tenha habilitação para o magistério.

Desdeentão, tem sido comum ver o Instrutor de Libras ser descrito em diversos textos, didáticos e/ ou acadêmico-científicos, como um sujeito surdo que atua no ensino de Libras dentro das escolas. É identificado como um profissional com surdez, ou seja, o profissional surdo que atua na escola tem sido chamado comumente de Instrutor de Libras, mesmo tendo habilitação para o magistério e atuando como professor.

Damázio e Ferreira (2010) fazem essa colocação e identificam que os Instrutores são profissionais preferencialmente com surdez que ensinam Libras nas escolas para os educandos surdos:

Para oferecer o aprendizado dessa língua de forma significativa, resguardando que seus usuários tenham a apropriação de maneira natural, é importante a presença de profissional com surdez, se possível, nesse ambiente. Esse trabal ho tem sido executado por instrutores de Libras (preferencialmente, por profissionais com surdez) que têm a proficiência aplicada pelo MEC por meio da avaliação do Pró-Libras e, num futuro próximo, será ministrado por professores de Libras formados por cursos de Letras/ Libras (2010, p. 56).

A partir da colocação das autoras, observa-se que o Pró-Libras foi confundido com a habilitação para o magistério na Educação Básica. Entretanto, o Decreto 5.626/ 2005, por meio do Pró-Libras, não habilita para o exercício do magistério na educação bási ca sem a formação exigida na LDB 9694/ 1996, ou seja, o Instrutor de Libras aprovado no Pró-Libras não está apto para adentrar aos muros da escola e ensinar Libras, um componente curricular, aos educandos. Conforme citado, o Pró-Libras é um exame de certificação e proficiência para o exercício da função docente apenas na educação superior (Decreto 5626/ 2005, Art. 70). Porém, destaca-se que ao profissional Instrutor, a responsabilidades educativas são tão complexas quanto aquelas desempenhadas pelos professores.

Da mesma forma, o material didático "A tendimento Educacional Especializado - Deficiência Auditiva” do MEC, publicado em 2007, aponta indiscriminadamenteos dois profissionais, Instrutores eProfessores de Libras, como aquel es que desempenham funções similares, porém insistindo na nomenclatura diferenciada para o profissional surdo:

Estetrabalhado érealizado pelo professor e/ou instrutor deLibras (preferencialmente surdo), de acordo com o estágio de desenvolvimento da Língua de Sinais em que o al uno se encontra. $\mathrm{O}$ atendimento deve ser planejado a partir do diagnóstico do conhecimento que o aluno tem a respeito da Língua de Sinais. O professor e/ ou instrutor de Libras organiza o trabalho do A tendimento Educacional Especializado, respeitando as especificidades dessa língua (DAMAZIO, 2007, p. 32, grifo nosso). 
Além desses, Schimitt (2008) aponta a necessidade de ter surdos atuantes como Instrutores de Libras nas escol as dando aula para os al unos ouvintes. Cita o autor:

São poucos e é preciso expandir o curso de Língua de Sinais nas escolas com os instrutores dando aula de Libras para que o ouvinte entenda a cultura surda, identidade e movimentos surdos (p. 117 - 118).

Percebe-se que é o profissional surdo que tem sido identificado como Instrutor de Libras e tem assumido responsabilidades educacionais inerentes a um professor, fato que deveria ser suprido pelo Professor de Libras. Outra visão do Instrutor de Libras tem sido a de um profissional surdo que atua dentro da escola como apoio no ensino de Libras aos pais eprofessores das escolas de educação básica, conforme apontado no Documento de 1999 elaborado pela comunidade surda, citado acima. E, ainda nesta ótica, Quadros (2006, p. 154-155) se refere à existência de Professores ou Instrutores surdos em escolas de Santa Catarina. Ao refletir sobrea política do al uno surdo na educação básica em Santa Catarina afirma:

Os instrutores são os profissionais que vão participar do processo de aquisição da língua de sinais pelos al unos surdos. Quando isso passar a acontecer, de fato, os alunos não terão mais como model o apenas o seu professor que conhece um pouco a língua de sinais, mas vão poder contar com instrutores ou professores surdos que usam fluentementea sua língua. Além disso, essemesmo instrutor/professor teria a função de preparar o professor e o intérprete de língua de si nais, bem como ministrar os cursos para familiares (grifo nosso).

N essa perspectiva de Quadros (2006), o Instrutor de Libras também é citado como apoio às atividades da escola e, portanto, poderia se tratar do Trabalhador da Educação, descritos na Lei 12.014/2009, sendo aquele que possui formação técnica específica. Entretanto, ainda tem sido citado como aquele que participa do processo ensino-aprendizagem de formação do educando surdo no ensino da Librase, por isso, tem a docência como papel fundamental ou finalístico.

É preciso estar atento à questão discriminatória trazida pela nomenclatura de Instrutor de Li bras atuantes nas escolas de educação básica. Isso porque se faz comum a percepção de que justamente o sujeito surdo é que tem sido denominado de Instrutor de Libras, mesmo esse tendo além da formação pedagógica, as responsabilidades formativas inerentes aos docentes.

Deacordo com Silveira (on line), em pesquisa com professores surdos no ensino de Libras no Rio Grande do Sul, há necessidade de superar a utilização da nomend atura de Instrutor destinada exclusivamenteao profissional surdo. Mesmo não tendo a formação exigida, o surdo tem sido colocado na escola de Educação Básica para assumir a função docenteetem sido tratado como profissional secundário. De acordo com a autora, tal realidade produz impacto pejorativo na subjetividade desses profissionais e, portanto, faz-se necessário superar essa realidade: 
Há muita improvisação e até tem professores surdos, formados na FENEIS como instrutores de LIBRAS para dar aula aos ouvintes, que são contratados para serem professores na escola. Esta é uma situação transi tória, espero, que deve melhorar. (...)

Penso queéimportante para Educação deSurdos reconhecerem toda uma trajetória do que aconteceu desde o passado até agora.Também as reflexões sobre a importância das associações, dos surdos adultos como modelos para os surdos alunos, da necessidade de aumentar o número de professores surdos na escola, quenão fiquem como "secundários", foram pontos importantes queas entrevistas trouxeram (SILVEIRA, on line, p. 7-8).

Esse contexto indica a necessidade de se superar a atitude discriminatória ao denominar o Professor Surdo como um Instrutor de Libras em detrimento dos outros professores presentes nas escolas e que são responsáveis pel a formação integral do educando surdo. Por quenão tratá-lo tão somentecomo Professor de Libras? Já se identificou que o Instrutor de Libras, de acordo com o Decreto 5.626/ 2005 não está apto para o magistério da Educação Básica. Portanto, esse profissional, denominado de Instrutor de Libras é todo aquele que possui formação profissional eque poderá, portanto, atuar no ensino da Libras em cursos livres a ser oferecidos em empresas, instituições públicas, organizações e outros espaços, que não a educação formal.

A partir do momento em que um profissional surdo inicia sua atuação dentro da escola de educação básica, ele automaticamente deveria ser identificado como profissional da educação e Professor de Libras. Caso não tenha habilitação para o magistério, esse profissional surdo deveria ser encaminhado para curso de formação inicial, inclusiveem serviço. Então, passar a gozar detodas as conquistas que os profissionais da educação al cançaram em décadas de lutas pela melhoria da qualidade da educação. A ssim, contribuirá com a estruturação da sua identidade profissional, visto que, mais do que ensinar a sua própria língua, a Libras, esse profissional dentro da escola, está atuando para a formação integral do sujeito, desde aspectos afetivos, até aspectos culturais e de construção de conhecimento.

É reconhecida a importância do profissional da educação com surdez atuando na formação do educando surdo e, portanto, quando o profissional surdo tiver formação pedagógica, conforme exige a LDB, com título de licenciado, ele deve ser reconhecido como Professor, em igual dade de condições no que tange a aspectos profissionais e conquistas al cançadas pela profissão docente ao longo da história da educação brasileira. Nessa perspectiva, para que a chamada escola inclusiva real mente aconteça de forma que respeite a cultura ea identidade surda, além da construção do conhecimento do sujeito surdo, deve-se iniciar pelo reconhecimento dos saberes trazidos pelos profissionais surdos, reconhecendo-os sob a ótica da igualdade de condições para interferir no processo educativo da criança edo jovem com surdez, visto quemuitas vezes existem profissionais surdos já são graduados em cursos de licenciatura, entretanto, ainda sim, são chamados delnstrutores de Libras. 
O profissional surdo, Licenciado ou com curso N ormal, deveparticipar não somente do executar o ensino da Libras, mas da construção do projeto políticopedagógico, das discussões pedagógicas, das tomadas de decisão na escola, dos conselhos escolares, do grupo gestor, inclusive com o acompanhamento da aplicação dos recursos financei ros advindos do Fundeb ${ }^{7}$ e do Programa Dinheiro Direto na Escola, além de participar do debate da construção das escolas detempo integral e dos planos de carreira do profissional da educação, entre outros.

É preciso queo profissional surdo seja incluído também nas políticas de valorização do magistério das escolas públicas, com acesso à formação continuada, como direito do profissional da educação edever do poder público, com participação efetiva no acompanhamento e execução das políticas de educação inclusiva. Tratase da busca pela profissionalidade do profissional da educação com surdez.

Libâneo (2001) argumenta que as condições para garantir o exercício profissional referem-se à profissionalização, sendo, portanto formação inicial e continuada, com o desenvolvimento de competências e habilidades necessárias à profissão. Inclui-sena profissionalização uma remuneração compatível econdições materiais e técnicas de trabalho adequadas. O profissional, porém, deve ter profissional ismo, desempenhando sua função de forma compromissada com seus deveres e com responsabilidades específicas da docência, com atitudes éticas e políticas. O conjunto da profissionalização e profissional ismo levam à construção da profissionalidade desse sujeito.

A base deformação do profissional da educação éa docência, ea essência da docência envolve o processo ensino-aprendizagem. Dessa forma, o processo de aquisição da linguagem da criança surda, conformeérequerido do profissional surdo Instrutor de Libras, tem como essência o processo ensino-aprendizagem da Libras em contexto, imbuído de uma cultura linguística, de uma gramática própria e uma estrutura de construção de conhecimento peculiar. Portanto, o Instrutor de Libras, conforme vem sido referenciado, certamente atua eminentemente na função de magistério e sua presença no processo formativo da criança surda é essencial. É preciso possibilitar a este profissional, tratado como Instrutor de Libras surdo, atuantes nas escolas de educação básica, a formação inerente à docência, ou seja, a formação em Licenciatura ${ }^{8}$. Porém, mesmo tendo formação mínima exigida para o exercício do magistério, o seu reconhecimento não tem sido tomado pelo campo educacional a partir do momento em que tem sido tratado como Instrutor de Libras e não participa, muitas vezes, da construção da proposta educativa da escola. Por isso, evoca-se que possa ter seus saberes valorizados, sendo tratado em igualdade de condições, sendo, portanto, um Professor de Libras.

\footnotetext{
${ }^{7}$ Fundo deM Manutenção e Desenvolvimento da Educação Básica edeValorização dos Profissionais da Educação ${ }^{8}$ Em 2006, a Universidade Federal de Santa Catarina ofereceu o primeiro curso de Licenciatura em Letras: Libras a distância, com as provas do processo seletivo em Libras, possibilitando a aprovação de muitos profissionais surdos e o acesso à formação no magistério.
} 
N essas condições, o profissional surdo éessencial para segarantir uma educação de qualidade do sujeito com surdez eé dever do poder público contribuir para a construção de sua profissionalização, com formação inicial e continuada, remuneração condizente e condições de trabalho. Desse modo, o reconhecimento eval orização do sujeito surdo licenciado, Professor de Libras, éum primeiro passo para se conquistar essa educação inclusiva tão anunciada e requerida. Para isso, superar a nomenclatura de Instrutor de Libras é um passo primordial.

\section{REFERÊNCIAS}

A educação que nós surdos queremos. Documento elaborado pela comunidade surda a partir do pré-congresso ao V Congresso Latino Americano de Educação Bilingue para Surdos. Porto Alegre: S/ d, 1999. Disponível em: <http:/ / www.feneis.org.br/ arquivos/ A\%20EDUCA ÇÃ O\%20QUE\%20N ÓS\%20SURDOS\%20QUEREM OS.doc>. A cesso em: 13 jul.2010.

BRA SIL. Lei 10.436 - Dispõe sobre a Língua Brasileira deSinais - Libras e dá outras providências. Brasília, 2002.

. Lei n. 10.098 - Estabelecen ormas gerais e critérios básicos para a promoção da acessibilidade das pessoas portadoras de deficiência ou com mobilidadereduzida, edá outras providências. Brasília, 2000.

. MEC. Lei 12.014 - altera 0 art. 61 da LD B. Brasília, 2009.

. MEC. D ecreto n. 5.626 - Regulamenta a Lei no 10.436, de 24 de abril de 2002, que dispõe sobrea Língua Brasileira de Sinais - Libras, e o art. 18 da Lei no 10.098, de 19 de dezembro de 2000. Brasília, 2005.

. MEC. Lei de Diretrizes e Bases da Educação N acional - LDB 9.694 de 16 de dezembro de 1996. Brasília, 1996.

DAMÁZıO, M. F. M. A tendimento educacional especializado - pessoa com surdez. Brasília: MEC/ SEESP / SEED, 2007.

DAMÁZIO, M. F. M.; FERREIRA, J. P. Educação escolar de pessoas com surdez atendimento educacional especializado em construção. Inclusão: R evista deE ducação Especial , Brasília, v. 5, n.1, p. 46-57. 2010.

FELIPE, T. A. Políticas públicas para a inserção da Libras na educação de surdos. Espaço: informativo técnico-científico do IN ES, Rio de janeiro, n.25, 2006.

LIBÂNEO, J. C. O rganização e gestão da escola. Goiânia: Editora Alternativa, 2001.

LUNARDI, M. L. Cartografando os estudos surdos: currículo e relações de poder. In: SKLIAR, C. B. (Org.). A surdez: um ol har sobreas diferenças. Porto A legre: M ediação, 1998.

MAZZOTTA, M. J. S. Educação Especial no Brasil: história e políticas públicas. São Paulo: Cortez Editor, 2001. 
FARIA, J. G

QUADROS, R. M. Políticas lingüísticas e educação de surdos em Santa Catarina: espaço de negociações. Caderno CEDES, Campinas, v. 26, n. 69, 2006.

QUADROS, R. M.; PATERNO, U. Políticas linguísticas: o impacto do decreto 5626 para os surdos brasileiros. Espaço: informativo técnico-científico do IN ES, Rio de Janeiro, n. 25, 2006.

QUADROS, R. M. et al. ExameP rolibras. Florianópolis: s/ d, 2009. Disponível em: বhttp:/ / www.prolibras.ufsc.br/ livro_prolibras.pdf >. A cesso em: 11 jul. 2010.

SCHMITT, D. Espaço deconforto lingüístico/ cultural dos surdosna UFSC. In: QUADROS, R. M. (Org.). Estudos Surdos III. Petrópolis: Arara Azul, 2008.

SILVEIRA, C. H. 0 ensino delibras para surdos - uma visão de professores surdos. Disponível em: বhttp:/ / online.unisc.br/ seer/ index.php/ reflex/ article/ viewFile/ 576/ 520>. A cesso em: 11 jul. 2010.

SILVEIRA, C. H.; REZENDE, P. L. F. Os discursos sobre a educação de surdos na revista Nova Escola. In: QUA DROS, R. M. (Org.). Estudos Surdos III. Petrópolis: A rara Azul, 2008.

SOARES, M. A. L. A Educação do Surdo no Brasil. Campinas: A utores Associados, EDUSF, 1999.

TANURI, L. M. História da formação de professores. Revista Brasileira de E ducação. Brasília, n. 14, 2000.

Recebido: 23/ 07/ 2010

Reformulado: 08/ 02/ 2011

A provado: 04/ 04/ 2011 